\title{
Circuit
}

Musiques contemporaines

\section{Das Einfachste, schwer zu machen [Bertolt Brecht]}

\section{Brice Pauset}

Volume 15, numéro 3, 2005

Souvenirs de Darmstadt : retour sur la musique contemporaine du dernier demi-siècle

URI : https://id.erudit.org/iderudit/902371ar

DOI : https://doi.org/10.7202/902371ar

Aller au sommaire du numéro

\section{Éditeur(s)}

Les Presses de l'Université de Montréal

ISSN

1183-1693 (imprimé)

1488-9692 (numérique)

Découvrir la revue

Citer cet article

Pauset, B. (2005). Das Einfachste, schwer zu machen [Bertolt Brecht]. Circuit, 15(3), 71-72. https://doi.org/10.7202/902371ar

\section{Résumé de l'article}

En prenant la gare de Darmstadt comme métonymie, le compositeur français, qui a fréquenté les Ferienkurse au cours des années 1990, les décrit sous le double signe de la ruine et du consumérisme. Il n'exclut pourtant pas que puisse s'y manifester quelque forme de transcendance. d'utilisation que vous pouvez consulter en ligne.

https://apropos.erudit.org/fr/usagers/politique-dutilisation/ 


\title{
Das Einfachste, schwer zu machen' [Bertolt Brecht]
}

\author{
Brice Pauset
}

Darmstadt, avant et après les Ferienkurse, c'est d'abord (et pour finir) une gare, je dirais même, croisant le lexique anglais, une station, comme lorsqu'on parle des stations du calvaire qu'adorent les chrétiens. Un bref moment d'attente sur les quais de cette gare est amplement suffisant pour saisir une métaphore possible de ce que sont devenues maintenant les quelques semaines de cours à Darmstadt, qui se tiennent encore aujourd'hui dans les murs de l'inaltérable Georg Büchner Schule, débarrassée estivalement de ses habituels étudiants.

La gare de Darmstadt est un lieu situé très exactement au point d'équilibre du bâtiment fonctionnel et de la ruine : les trains y circulent approximativement à l'heure, tandis que d'inattendues variétés de plantes plus ou moins continentales foisonnent sur le ballast des voies, et que le béton dont sont faits les abris de quai, diversement fissuré, laisse entrevoir çà et là, par la rouille qu'il dispense de plus en plus généreusement, les côtes fatiguées de son squelette ferreux.

Une pure fonction et une ruine, telle pourrait être la double et malheureuse définition de ce que sont devenus les cours dispensés chaque été, tant le pragmatisme sous toutes ses formes, des plus ostensibles aux plus inavouables, a, semble-t-il, définitivement enterré toute velléité d'appétit utopique, au profit bien maigre d'une ligne additionnelle à insérer dans la biographie des étudiants en visite, ligne destinée en principe à éclairer le futur lecteur (généralement le jury d'un concours dit international ou le comité chargé de choisir sur dossier les nouvelles recrues de tel ou tel conservatoire) sur les intentions idéologiques de l'intéressé. Je parle ici, bien évidemment, de ce que j'ai observé lors de mes différents passages qui ont eu lieu irrégulièrement et parfois discrètement à partir du début des années 1990.
1. Rendre difficile ce qui est le plus simple. Tiré de la fin du poème "Éloge du communisme" qui se trouve dans une pièce intitulée La Mère (écrite d'après le roman de Maxime Gorki), publiée dans Bertolt Brecht (1959), Théâtre complet, t. 3, Paris, L'Arche, p. 172-173. La fin du poème, "Er ist das Einfache, Das schwer zu machen ist" est traduite par : "Il est chose simple, Difficile à faire".

Nous remercions Yves Saint-Amant pour cette explication. 
La gloire passée (oui, le climat des cours d'été de Darmstadt a été autrefois exalté, sinon glorieux) mêlée à l'aura présumée de paternités admirées se transforment très diversement chez les actuels invités et visiteurs; elles agissent notamment comme puissant révélateur de plans de carrière. Des mythologies variées (au parfum le plus souvent éventé) revêtent une efficace fonction commerciale : l'incompréhensibilité de schémas censés analyser les arcanes du dernier chef-d'œuvre du conférencier impressionne presque toujours et laisse supposer une intelligence spéculative très au-dessus de la moyenne («c'est sûrement très bien; d'ailleurs on n'y comprend rien »); tel compositeur extrême-oriental utilisant à satiété le kitsch des clichés (occidentaux) de la musique japonaise aura là-dessus un discours tour à tour allusif, mystérieux, naîf : il faudra l'inviter régulièrement si l'on veut y voir clair un jour (le tour est joué). Le professionnel de l'efficacité, lui, fera montre d'un grand dédain visà-vis de tout ce qui, de près ou de loin, touche à l'abstraction, à la spéculation, à la tentative, à une certaine fragilité; seules les solides recettes - celles qui marchent à tous les coups - sont réellement efficaces : un algorithme bien habillé peut faire illusion le temps d'une carrière entière.

Ce qui m’a troublé et qui peut-être ne serait pas arrivé il y a une cinquantaine d'années, c'est la perméabilité malheureuse de cette institution à l'air du temps : celui de la fin de l'histoire, de l'abandon des choix possibles, de la post-démocratie et du fonctionnalisme pragmatique; un air du temps qui réussit progressivement à donner à l'adjectif intellectuel une tonalité péjorative et, comme on dit en allemand, altmodisch. Darmstadt devrait être au contraire, me semble-t-il, emblématique de positions courageuses dépassant les faux antagonismes de la culture réifiée, acceptant, le cas échéant, de revenir sur certaines positions réputées fondatrices; de ce point de vue, la musique de Webern (sa dernière période en particulier) devrait faire l'objet d'une ré-interprétation radicalement autre. Le tout, sans dogmatisme(s): nostalgie post-sérielle, orthodoxie spectrale à la française (américanisée ou non), néo-déterminismes computationnels variés, et tous les autres.

Et puis, il y a les cas particuliers. Ils sont exceptionnels (c'est normalement leur nature) mais ils existent. Une compositrice, lors de sa conférence, va expliquer, sans s'aider des béquilles confortables du camouflage verbeux, pourquoi et comment elle écrit la musique qui lui semble nécessaire. Elle a donné à penser sur sa musique, sur ce que c'est au juste que la musique.

Ailleurs sur les pelouses jaunies de soleil de la Georg Büchner Schule, j'ai pu voir un jeune flûtiste nippon élever l'interprétation de Unity Capsule de Brian Ferneyhough au rang d'art martial, voire d'ascèse mystique. J'en frissonne encore. 